\title{
The biomechanical consequences of longirostry in crocodilians and odontocetes
}

\author{
McCurry M.R. ${ }^{1,2,3}$, Walmsley C.W. ${ }^{1}$, Fitzgerald E.M.G. ${ }^{2,5,6}$, McHenry C.R. ${ }^{1,7,8}$
}

1. Monash Biomedicine Discovery Institute and Centre for Human Anatomy Education, Department of Anatomy and Developmental Biology, Monash University, Melbourne, Australia

2. Geosciences, Museums Victoria, Melbourne, Australia

3. Department of Paleobiology, National Museum of Natural History, Smithsonian Institution, Washington, DC, USA

4. School of Biological Sciences, Monash University, Melbourne, Australia

5. Department of Vertebrate Zoology, National Museum of Natural History, Smithsonian Institution, Washington, DC, USA

6. Department of Life Sciences, Natural History Museum, London, UK

7. School of Environmental and Life Sciences, The University of Newcastle, Newcastle, Australia

8. School of Engineering, The University of Newcastle, Newcastle, Australia

Key words: Finite element analysis, Skull, Feeding, Crocodilia, Odontoceti, Convergent evolution.

Competing interests: We have no competing interests.

Word count: 3947

Authors' contributions: All authors were involved in the study and preparation of the manuscript. The material within has not been and will not be submitted for publication elsewhere.

\section{Abstract}


Unrelated clades of aquatic tetrapod have evolved a similar range of skull shapes, varying from longirostrine (elongate and narrow rostrum) to brevirostrine (short rostrum). However, it is unclear which aspects of organismal performance are associated with this convergence in the range of skull shapes. Furthermore, it is not known how fundamental anatomical differences between groups influence these relationships. Here we address this by examining the load bearing capabilities of the skulls of two of the most diverse groups of living aquatic tetrapod: crocodilians and odontocetes. We use finite element analysis to examine the abilities of different cranial morphologies to resist a range of biologically relevant feeding loads including biting, shaking and twisting. The results allow for form/function relationships to be compared and contrasted between the two groups. We find that cranial shape has similar influences on performance during biting, shaking or twisting load cases at the anterior tooth positions, e.g. brevirostrine species experienced less strain than longirostrine species. The pattern of this form/function relationship is similar for both crocodilians and odontocetes, despite their fundamentally different anatomies. However, when loading teeth at the posterior end or middle of the tooth row the results do not follow the same pattern. Behavioural differences in bite location plays a key role in determining functional abilities in aquatic tetrapod taxa.

\section{Introduction}

Living crocodilians and odontocetes (toothed whales) have evolved a similar range of variation in rostral shape, varying from longirostrine with an elongate and narrow rostrum, to brevirostrine with a short and broad rostrum (Brochu, 2001; McHenry et al., 2006; Walmsley et al., 2013b). Elongation of the rostrum is also associated with a relatively longer mandibular symphysis in the most longirostrine taxa (e.g. river dolphins or gharials) (Walmsley et al., 2013b). Within crocodilians longirostry is also associated with a loss of pseudoheterodonty (differences in tooth size) and a loss of undulation in the jaw margins (Cleuren and De Vree, 2000). Busbey (1995) classified longirostrine 
crocodilians as those with rostral length/condylobasal length values over 0.7 , mesorostrine crocodilians as those with values between 0.55 and 0.7 , and brevirostrine crocodilians as any with values under 0.55 . The morphology of the skull within this spectrum (brevirostrine-longirostrine) has been hypothesised to relate to the functional and ecological limitations of the species (McHenry, 2009; McHenry et al., 2006; Walmsley et al., 2013b). Specifically, it has been suggested that brevirostrine morphotypes are able to handle higher loads during feeding, an adaptation that would allow them to feed on larger or harder prey (Busbey, 1995; McHenry et al., 2006; Walmsley et al., 2013b). Extensive analyses have been undertaken on the load bearing and force producing capabilities of crocodilian cranial systems (Busbey, 1989; Busbey, 1995; Cleuren and De Vree, 2000; Erickson et al., 2012; Erickson et al., 2003; McHenry et al., 2006; Pierce et al., 2008; Porro et al., 2011; Rayfield et al., 2007; Reed et al., 2011; van Drongelen and Dullemeijer, 1982; Walmsley et al., 2013b) but no studies have directly compared their functional abilities to odontocetes to understand exactly why these different groups have evolved such a similar range of morphologies.

Crocodilians and odontocetes are often used as extant morphological and ecological analogues for extinct marine tetrapods such as archaeocetes, ichthyosaurs, thallatosuchians and pliosaurs because of their similarities in body form, limb shape and rostral proportions (Massare, 1987, 1988; Walmsley et al., 2013b; Young et al., 2012). While crocodilians, odontocetes and these extinct marine reptile groups qualitatively appear to have a similar range of cranial variation, varying in rostral dimensions from short and broad through to elongate and slender (Walmsley et al., 2013b), we still do not know whether these similarities in morphology translate to performance characteristics. Identifying similar form/function relationships between aquatic reptiles and mammals is a necessary step before using living odontocetes or crocodilians to predict the biomechanical and ecological characteristics of extinct taxa.

Furthermore, while odontocetes and crocodilians occupy similar aquatic environments and feed using similar raptorial feeding" tactics, they vary considerably in other aspects of sensory biology and 
feeding behaviour. These differences in sensory biology and feeding behaviour are reflected in the anatomy of the skull (Figure 1). Odontocetes have the ability to produce suction to aid in feeding, although the use of this tactic varies considerably between species, with some species only using suction for intra-oral transport (Bloodworth and Marshall, 2005; Werth, 2000, 2006a; Werth, 2006b). Within the skull this influences the shape of the mandible as well as the palate morphology, with suction feeding specialists having blunter mandibles and more highly vaulted palates (Werth, 2006a). Crocodilians also engage in some prey processing behaviours not undertaken by odontocetes, including twisting off pieces of prey using a "death roll" (Fish et al., 2007). In terms of sensory ability, odontocetes have the ability to echolocate prey using specialised sound production and reception organs such as the melon and phonic lips (Nachtigall, 1980). The odontocete mandible also plays a role in echolocation by allowing sound to be received by the ear through an extremely thin section of bone in the posterior of the mandible called the pan bone (Norris, 1968) (Figure 1). In crocodilians this posterior region of the mandible acts to withstand biting forces generated by the jaw muscles (Walmsley et al., 2013b). Crocodilians also possess pterygoid flanges (Figure 1) that act to prevent medial bending of the mandible during loading (Porro et al., 2011). It is unclear to what extent these morphological differences might alter the fundamental form/function relationships that could be expected in a range of brevirostrine-longirostrine morphologies.

Predictions of the mechanical response of brevirostrine - longirostrine forms can be generated using principles such as beam theory (Bauchau and Craig, 2009; Metzger et al., 2005; Walmsley et al., 2013b), but applying beam theory to capture the morphological differences between phylogenetically disparate taxa is very difficult. Testing how well form/function relationships match basic predictions requires an approach that can account for complex differences in morphology. Finite element analysis is a modeling technique that can predict the response of complex structures to applied load using numerical methods. Previous studies using this technique have shown that the cranial morphology of a species often relates to its preferences in feeding (Dumont et al., 2005; 
McCurry et al., 2015b; McHenry et al., 2007; Moreno et al., 2008; Soons et al., 2010). Here we aim to use finite element analysis to:

1) Determine whether longirostry has similar effects on structural performance during biting, shaking and twisting in crocodilians and odontocetes.

2) Examine the effects of differences in anatomy between crocodilians and odontocetes on the location and magnitude of strain.

We hypothesise that more longirostrine morphotypes will exhibit higher levels of strain than more brevirostrine morphotypes during all loading scenarios (biting, shaking and twisting at any tooth position). This is expected to occur in a relative sense (e.g. patterns within each group) rather than in an absolute sense.

\section{Methods}

\subsection{Specimen selection and mesh generation}

Specimens were accessed from the Field Museum of Natural History (FMNH), The Australian Museum Mammalogy and Herpetology collections (AMM and AMR), Museum Victoria Vertebrate Zoology collections (NMVC), The National Museum of Natural History Vertebrate Zoology collections (USNM) and Texas Memorial Museum Vertebrate Paleontology Laboratory (TMM). The cranium and mandible of four species of crocodilian (Osteolaemus tetraspis - FMNH 98936, Crocodylus novaeguineae - AMR 24446, Mecistops cataphractus - TMM M-3529 and Tomistoma schlegelii TMM M-6342) and four species of odontocete (Orcinus orca - AMM 22839, Lagenorhynchus australis - USNM 395614, Stenella longirostris - NMV C28276 and Inia geoffrensis - USNM 395614) were CT scanned at various locations in medical or industrial CT scanners. Scan resolution varied from 0.054 $\mathrm{mm} \times 0.054 \mathrm{~mm} \times 0.11 \mathrm{~mm}$ in the highest resolution scan (Osteolaemus tetraspis) to $0.976 \mathrm{~mm} \times$ $0.976 \mathrm{~mm} \times 1 \mathrm{~mm}$ in the lowest resolution scan (Orcinus orca). Sensitivity studies indicate that this 
range of variation in scan resolution are not expected to influence the comparative results (McCurry et al., 2015a). These taxa were chosen to represent a similar range of variation in the external morphology of the rostrum and mandible varying from longirostrine e.g. the false gharial (Tomistoma schlegelii) and the Amazon river dolphin (Inia geoffrensis), through to brevirostrine e.g. the killer whale (Orcinus orca) and the dwarf crocodile (Osteolaemus tetraspis). These specimens are likely to differ in their internal morphology, but here we focus on external morphological characteristics.

The CT data were digitally segmented (digitally isolated) in MIMICS V15 to create surface models that were consistent in terms of the morphological features that were included. This involved digitally filling any foramina that were smaller than the mandibular canal as well as removing items such as specimen tags that were tied to the specimens. The surface models were converted into solid tetrahedral (tet4) models, composed of approximately 2 million cranial elements and 1 million mandibular elements using Harpoon (V4.3). Different element sizes were used in the mandible and cranium of the odontocetes to allow for enough thickness in the thin pan bone whilst still keeping within our bandwidth limits. Crocodilian models were reused from Walmsley et al. (2013b).

\subsection{Finite element modeling}

Finite element modeling was undertaken in Strand7 (V2.4.4) using the linear static solver. Due to an absence of published material properties for odontocete cranial bone we assigned the odontocete models with material properties for bovine femur - Young's modulus = 18.7 GPA (Currey, 1987), Poisson's Ratio $=0.34$ (Grenoble et al., 1972). The crocodilians were assigned material properties of Alligator femur and mandible - Young's modulus $=11.9$ GPA (Currey, 1987), Poisson's Ratio $=0.4$ (Zapata et al., 2010). The isotropic Young's modulus values were used here in preference over more detailed anisotropic materials that are available for Alligator mandibles (Zapata et al., 2010) to avoid comparing anisotropic crocodilian models to isotropic odontocete models. Material properties were also assigned as homogeneous. Strain is directly proportional to Young's Modulus, where a larger 
modulus will yield a smaller strain value for a given load/stress. Because of this, the results within either crocodilians or odontocetes can be viewed as the result of differences in morphology, and results between the two groups can be interpreted as the result of differences in morphology and generalised differences in mammalian and crocodilian material properties.

All models were scaled to the same volume as the $M$. cataphractus model of $507889 \mathrm{~mm}^{3}$ to account for size (Dumont et al., 2009; Walmsley et al., 2013a). Muscles were simulated in the models using 298 beam elements (SUP1 and SUP2). The locations of the muscle attachment sites were chosen based on published accounts of jaw muscle anatomy for odontocetes (Seagars, 1982) and crocodilians (Holliday, 2009; lordansky, 1964). In crocodilians the interaction between the pterygoid flanges and the mandible prevents medial bending of the mandible (Porro et al., 2011). Here we simulated this using a link element between the relevant surfaces on the pterygoid and mandible, which allowed all movements except medial translation of the mandible.

Six intrinsic bite load cases were simulated:

Bite loads where the relevant teeth (either anterior, middle or posterior) were restrained in both lateral translation and translation around the jaw hinge axis (Figure $2 \mathrm{~A})$. The occipital condyle was restrained by one node in all degrees of translation and rotation and muscle forces were applied to the models through the muscle beam elements. The forces applied through these beams were based on the cross-sectional areas of each of the muscles that were estimated using the dry skull method for mammals (Thomason, 1991) and adapted for crocodilians (McHenry, 2009). The results were then scaled using the linear load case combination function of Stand 7 to produce the following results cases.

Bite force scaled results that represent the models being loaded to perform the same ecological function such as breaking the same prey item: 
1) Bite loading at the anterior teeth with muscle forces set to produce the same node reaction forces at the teeth.

2) Bite loading at the middle teeth with muscle forces set to produce the same node reaction forces at the teeth.

3) Bite loading at the posterior teeth with muscle forces set to produce the same node reaction forces at the teeth.

Differences in the input muscle forces are shown in Table 1.

Muscle force scaled results that represent the models being loaded with the same total muscle force (with consequent variation in bite forces as a result of differing outlever lengths):

4) Bite loading at the anterior teeth with muscle forces set the same force.

5) Bite loading at the middle teeth with muscle forces set the same force.

6) Bite loading at the posterior teeth with muscle forces set the same force.

In addition, four extrinsic load cases were simulated. Within these load cases the muscles were not applied with a pretension but remained within the models as bracing structures.

7) Shake loading at the anterior teeth where a force of $400 \mathrm{~N}$ was applied laterally in the direction of the jaw hinge axis.

8) Shake loading at the middle teeth where a force of $400 \mathrm{~N}$ was applied laterally in the direction of the jaw hinge axis.

In these shake loading cases the occipital condyle was restrained in space using two nodes fixed in all degrees of translation and rotation (Figure $2 \mathrm{~B}$ ).

9) Twist loading at the anterior teeth where a rotational moment of $400 \mathrm{Nmm}$ was applied around an axis created between the tip of the rostrum and the midline of the occipital condyle. 
10) Twist loading at the middle teeth where a rotational moment of $400 \mathrm{Nmm}$ was applied around an axis created between the tip of the rostrum and the midline of the occipital condyle.

In twist loading, one node was used to fix the occipital condyle in all three degrees of translation. The relevant teeth (either anterior or middle) were also fixed in translation around the jaw hinge axis and in the lateral direction (Figure $2 \mathrm{C}$ ).

As well as qualitative visual comparisons, $95 \%$ values were generated using the $\mathrm{R}$ code following the methods of McCurry et al. (2015b) and Walmsley et al (2013b). These values represent the peak strain within the model if the top $5 \%$ of strain values are removed. This method allows for the models to be compared with reduced influence of localised strain artefacts at the loading and constraint sites which often represent the highest levels of strain within the models (McCurry et al., 2015b; Walmsley et al., 2013b).

\section{Results}

\subsection{Bite force scaled bite loads}

During bite force scaled bite loading scenarios at the anterior teeth the two most brevirostrine odontocetes experienced less strain than the most longirostrine odontocetes (Figure $3 \mathrm{~A}-\mathrm{H}$ and Figure 4). In all taxa bite loading resulted in high strain in the posterior of the palate. Within the odontocete models high levels of strain primarily occurred in the thin pan bone at the posterior of the mandible, the lateral margin of the maxilla and the dorsal surface of the rostrum (Norris, 1968). Strain was low throughout most of the basicranium. In the crocodilians high levels of strain occurred on the dorsal boundary of the maxilla and the dorsal surface of the rostrum (Figure $3 \mathrm{E}-\mathrm{H}$ ).

During bite loading scenarios at the middle tooth position, odontocetes exhibited high levels of strain in the pan bone, within the mandible directly ventral to the teeth that were restrained, within 
the interorbital region and on the surface of the temporal fossa. Within crocodilians high levels of strain also occurred in the interorbital space and in the posterior of the mandible (Figure $3 \mathrm{I}-\mathrm{P}$ ).

During bite loading scenarios at the posterior tooth position high levels of strain occurred in the pan bone of the odontocetes and throughout most of the anterior mandible of the brevirostrine species but not the anterior mandible of Inia. Within the crocodilians high levels of strain also occur in the nasals as well as in the posterior sections of the braincase (Figure $3 \mathrm{Q}-\mathrm{X}$ ).

In most bite force scaled load cases the odontocete mandibles exhibited higher levels of strain than the crocodilians. In anterior bite load cases there was a relatively similar pattern of performance between the morphotypes, with longirostrine taxa experiencing higher levels of strain than brevirostrine taxa (Figure 4 A). In posterior biting load cases this was not the case, the longirostrine odontocetes actually exhibited less strain than the brevirostrine species (Figure $4 \mathrm{C}$ ). In all bite force scaled biting simulations the models experienced considerably higher levels of strain within the mandible compared to the cranium. In all biting scenarios the locations in which strain occurred within the rostrum was reasonably consistent between crocodilians and odontocetes of the same morphotype, e.g. longirostrine crocodilians and odontocetes experiences strain in similar regions (Figure 3 and SUP3).

\subsection{Muscle force scaled bite loading}

When the models were loaded with the same muscle force and restrained at the anterior tooth position the crania of more longirostrine crocodilians exhibited higher levels of strain. Longirostry in odontocetes followed the same pattern in the cranium with longirostry resulting in higher levels of strain. Longirostry also resulted in higher levels of strain in the mandibles of the crocodilian species. However, within the odontocete models the pattern was different, the longirostrine $S$. longirostris model experienced less strain than all other models (Figure $5 \mathrm{~A}$ ). The mandible of $L$. australis also responded with higher levels of strain in the mandible than was expected. Strain occurred in the pan bone in these load cases, which could indicate that this region of the skull is better adapted to 
handle bite loads in the some longirostrine taxa. It could also be that some odontocete taxa are better adapted for producing low bite forces and hence respond with high strain when bite force is standardised, but lower strain when muscle force is standardised. The differences in the patterns observed between crocodilians and odontocetes here might also be the result of At the middle and posterior positions this relationship between longirostry and structural performance was not present, e.g. the longirostrine crocodilians performed equally as well as brevirostrine crocodilians (Figure $5 \mathrm{~B}$ and $\mathrm{C}$ ).

\subsection{Shake loading}

In shake loading scenarios at the anterior teeth strain patterns were qualitatively similar in both the crocodilians and the odontocetes. High levels of strain occurred anterior to the pan bone in odontocetes as well as within the posterior edge of the mandibular symphyses in both odontocetes and crocodilians (Figure 6 and Figure 7).

During anterior shake load cases the longirostrine taxa all exhibited higher strain than the brevirostrine taxa. However, in shake load cases at the middle dentition the longer, thinner-snouted Inia geoffrensis model performed better than the slightly broader snouted Stenella longirostris model. High levels of strain occur anterior to the pan bone in odontocetes as well as the mandibular symphyses in both odontocetes and crocodilians (Figure 6 and Figure 7). All of the crocodilian models, with the exception of Osteolaemus tetraspis had lower levels of strain in the mandible than the cranium. In comparison, most of the odontocete skulls exhibited similar levels of strain in the cranium and mandible during shaking simulations. In all shaking scenarios the crocodilians responded with higher levels of strain in the posterior palate and skull roof compared to the odontocetes, other than this locations was reasonably consistent between crocodilians and odontocetes of the same morphotype (Figure 6 and SUP4).

\subsection{Twist loading}


During twist loading scenarios strain occurred throughout the rostrum and mandible posterior to the teeth that were restrained in both crocodilians and odontocetes (Figure 8). The crocodilians and odontocetes exhibited similar levels of strain (Figure 9). When loaded at the anterior teeth, longirostrine taxa exhibited higher levels of strain than brevirostrine taxa. When loaded at the middle tooth position the crocodilians still followed this pattern, however the cranium of Inia geoffrensis outperformed that of the Stenella longirostris model. In all twisting scenarios the locations in which strain occurred within the rostrum was reasonably consistent between crocodilians and odontocetes of the same morphotype (Figure 8 and SUP5).

\section{Discussion}

\subsection{The biomechanical consequences of longirostry}

Here we set out with the goal of understanding how convergent similarities in cranial morphology in crocodilians and odontocetes manifested in similar biomechanical performance. When we loaded the models at the anterior tooth positions our results supported the hypothesis that longirostrine morphotypes of both crocodilians and odontocetes exhibit higher levels of strain. This trend held true in biting, shaking and twisting scenarios at the anterior dentition. However, when loaded at the posterior end of the tooth row, our results did not support this hypothesis; longirostrine odontocetes yielded very different results to crocodilians, exhibiting lower levels of strain than more brevirostrine morphotypes. These results indicate that brevirostrine morphotypes better handle high loading at the anterior dentition. The results also indicate that longirostrine morphotypes can be structurally resilient when loaded at the posterior of the tooth row.

The observation that the Amazon River dolphin (Inia geoffrensis) with its hyper-elongate morphology performed better than all other odontocetes during bite force scaled load cases with the posterior teeth was unexpected. However, this result is consilient with published records of the 
species feeding on hard-shelled river turtles in the genus Podocnemis (Da Silva and Best, 1982). It is possible that the long mandibular symphysis of this longirostrine odontocetes acts to prevent strain during posterior loading by bracing the mandible against the medial pull of the jaw muscles. A characteristic that wouldn't be necessary in the crocodilians due to the function of the pterygoid buttress. However, additional simulations of other river dolphins would be necessary to determine whether this result is caused by shared morphological features or whether it is unique to the Amazon River dolphin.

These results have interesting implications for our understanding of fossil taxa, as longirostrine taxa are often regarded as functional or ecological specialists (Cassens et al., 2000; Cuff and Rayfield, 2013; McHenry et al., 2006). Our results indicate that by undertaking specific behaviours (feeding with the posterior dentition) this morphotype may not necessarily be limited in its abilities to withstand high loads. The evolution of longirostrine morphotypes may instead represent a widening of abilities, where the length of the snout allows for greater angular acceleration and greater speed during sweep feeding (McHenry et al., 2006), whereas and posterior sections of the snout still allow for load bearing capabilities necessary for producing high bite forces and resisting high loads (McHenry, 2009). However, it is unclear whether longirostrine morphotypes are able to safely employ this behaviour on all prey items. It is easy to imagine large or agile prey items being difficult to catch without using the end of the rostrum which is less structurally adept in longirostrine taxa than in brevirostrine taxa.

\subsection{The functional effects of anatomical differences between crocodilians and odontocetes}

Differences in the anatomy of crocodilians and odontocetes did result in some differences in the location and magnitude of strain. For instance, the mandibles of odontocetes experienced higher levels of strain than those of crocodilians during muscle force standardised load cases. We think that this is both caused by the presence of the thin pan bone of odontocetes as well as the absence of the pterygoid flanges which prevent medial bending in crocodilians. The radical differences in the 
structure of the brain case also resulted in variation in the location of strain. Interestingly, the odontocetes performed equally as well as the crocodilians during twisting behaviours, indicating that the skull of odontocetes is capable of performing this behaviour even though it has not been observed.

Despite differences in the function of the posterior mandible and brain case, within the rostrum and the anterior mandible strain patterns were remarkably consistent between crocodilians and odontocetes. Strain occurred in similar regions between similar morphotypes (e.g. brevirostrine crocodilians and odontocetes showed similarities in the location and magnitude of strain). Our results show that crocodilians and odontocetes have evolved a similar range of cranial morphologies that function in similar ways even though they have distinct phylogenetic histories and differences in the number and position of skeletal elements.

\subsection{Limitations}

Our study did not assess the performance of suction feeding morphotypes such as the pygmy sperm whale (Kogia breviceps) or the narwhal (Monodon monoceros), which despite being brevirostrine are likely to have very different performance characteristics to the killer whale (Orcinus orca). These suction feeding morphotypes probably exhibit different patterns and levels of strain as they do not encounter high loads. This study also did not incorporate the use of soft tissues as structural elements, or sutures which have been shown to be important in altering strain patterns (Reed et al., 2011). Because of these limitations the results presented here should only be interpreted in a comparative context and not compared in an absolute sense to the work of other studies.

\subsection{Conclusions}

Crocodilians and odontocetes represent key model organisms for understanding the paleoecology of extinct aquatic tetrapod taxa such as archaeocetes, ichthyosaurs, thallatosuchians and pliosaurs. Despite similarities in the overall morphology in species of crocodilian, odontocete and these extinct 
groups, they do differ in aspects of their anatomy. Here we tested how similarities and differences in morphology extant crocodilians and odontocetes effect form/function relationships. The results support the hypothesis that brevirostrine morphotypes are better adapted to handle loading at the anterior dentition than longirostrine morphotypes. Anatomical differences did influence the locations and magnitudes of strain but for anterior loading scenarios the form function relationships were still similar. Interestingly, longirostrine morphotypes are not necessarily limited in their ability to handle forces at the posterior dentition. This result alone causes us to rethink how we interpret the functional abilities of longirostrine taxa, both living and extinct.

\section{Acknowledgments}

The authors acknowledge Matthew Colbert and Jesse Maisano (Digital Morphology, University of Texas) and Chris Brochu (University of lowa) for access to CT data. We thank Eleanor Cunningham (Newcastle Mater hospital), Mason Meers (University of Tampa), Janine Hinton (National Museum of Natural History) and Bruno Frohlich (National Museum of Natural History) for scanning of specimens. Ross Sadlier and Cecilie Beatson (Australian Museum), as well as Katie Date and Karen Roberts (Museum Victoria) provided access to specimens. We would also like to thank Alistair Evans, Justin Adams and Nicholas Pyenson for useful discussion on the topic. Work was funded by Australian Research Council Discovery Project grants DP0986471 (to CRM), Monash University internal funding (to CRM), a grant from The Joyce W. Vickery Scientific Research Fund (to MRM), a Museum Victoria 1854 student scholarship (to MRM), a Monash University/Museum Victoria collaborative research scholarship (to MRM) and a Peter Buck Predoctoral Fellowship from the Smithsonian Institution (to MRM). The funders had no role in study design, decision to publish or preparation of the manuscript.

Conflict of interest statement: We have no competing interests. 


\section{References}

Bauchau, O., Craig, J., 2009. Euler-Bernoulli beam theory, Structural analysis. Springer, pp. 173-221. Bloodworth, B., Marshall, C.D., 2005. Feeding kinematics of Kogia and Tursiops (Odontoceti: Cetacea): characterization of suction and ram feeding. Journal of Experimental Biology 208, 37213730.

Brochu, C.A., 2001. Crocodylian snouts in space and time: Phylogenetic approaches toward adaptive radiation. American Zoologist 41, 564-585.

Busbey, A.B., 1989. Form and function of the feeding apparatus of Alligator mississippiensis. Journal of Morphology 202, 99-127.

Busbey, A.B., 1995. The structural consequences of skull flattening in crocodilians. Cambridge Univ Press, Cambridge.

Cassens, I., Vicario, S., Waddell, V.G., Balchowsky, H., Van Belle, D., Ding, W., Fan, C., Mohan, R.L., Simões-Lopes, P.C., Bastida, R., 2000. Independent adaptation to riverine habitats allowed survival of ancient cetacean lineages. Proceedings of the National Academy of Sciences 97, 11343-11347.

Cleuren, J., De Vree, F., 2000. Feeding in crocodilians. Feeding: form, function, and evolution in tetrapod vertebrates, 337-358.

Cuff, A.R., Rayfield, E.J., 2013. Feeding Mechanics in Spinosaurid Theropods and Extant Crocodilians. PLOS ONE 8, e65295.

Currey, J., 1987. The evolution of the mechanical properties of amniote bone. Journal of biomechanics 20, 1035-1044.

Da Silva, V., Best, R.C., 1982. Amazon river dolphin (Inia) preys on turtle (Podocnemis). Investigations on Cetacea 13, 253-256.

Dumont, E., Grosse, I.R., Slater, G.J., 2009. Requirements for comparing the performance of finite element models of biological structures. Journal of Theoretical Biology 256, 96-103.

Dumont, E.R., Piccirillo, J., Grosse, I.R., 2005. Finite-element analysis of biting behavior and bone stress in the facial skeletons of bats. The Anatomical Record Part A: Discoveries in Molecular, Cellular, and Evolutionary Biology 283, 319-330.

Erickson, G.M., Gignac, P.M., Steppan, S.J., Lappin, A.K., Vliet, K.A., Brueggen, J.D., Inouye, B.D., Kledzik, D., Webb, G.J.W., 2012. Insights into the ecology and evolutionary success of crocodilians revealed through bite-force and tooth-pressure experimentation. PLoS One 7, e31781.

Erickson, G.M., Lappin, A.K., Vliet, K.A., 2003. The ontogeny of bite-force performance in American alligator (Alligator mississippiensis). Journal of Zoology 260, 317-327.

Fish, F.E., Bostic, S.A., Nicastro, A.J., Beneski, J.T., 2007. Death roll of the alligator: mechanics of twist feeding in water. Journal of experimental biology 210, 2811-2818.

Grenoble, D.E., Katz, J.L., Dunn, K.L., Gilmore, R.S., Murty, K.L., 1972. The elastic properties of hard tissues and apatites. Journal of biomedical materials research 6, 221-233.

Holliday, C.M., 2009. New insights into dinosaur jaw muscle anatomy. The Anatomical Record:

Advances in Integrative Anatomy and Evolutionary Biology 292, 1246-1265.

lordansky, N., 1964. The jaw muscles of the crocodiles and some relating structures of the crocodilian skull. Anatomischer Anzeiger 115, 256.

Massare, J.A., 1987. Tooth morphology and prey preference of Mesozoic marine reptiles. Journal of Vertebrate Paleontology 7, 121-137.

Massare, J.A., 1988. Swimming capabilities of Mesozoic marine reptiles: Implications for method of predation. Paleobiology 14, 187-205.

McCurry, M.R., Evans, A.R., McHenry, C.R., 2015a. The sensitivity of biological finite element models to the resolution of surface geometry: a case study of crocodilian crania. PeerJ 3, e988. 
McCurry, M.R., Mahony, M., Clausen, P.D., Quayle, M.R., Walmsley, C.W., Jessop, T.S., Wroe, S., Richards, H., McHenry, C.R., 2015b. The Relationship between Cranial Structure, Biomechanical Performance and Ecological Diversity in Varanoid Lizards. PLoS ONE 10, e0130625.

McHenry, C., 2009. Devourer of Gods: The palaeoecology of the Cretaceous pliosaur Kronosaurus queenslandicus. University of Newcastle, Newcastle. http://hdl.handle.net/1959.13/935911

McHenry, C.R., Clausen, P.D., Daniel, W.J.T., Meers, M.B., Pendharkar, A., 2006. Biomechanics of the rostrum in crocodilians: A comparative analysis using finite element modeling. The Anatomical Record Part A: Discoveries in Molecular, Cellular, and Evolutionary Biology 288, 827-849.

McHenry, C.R., Wroe, S., Clausen, P.D., Moreno, K., Cunningham, E., 2007. Supermodeled sabercat, predatory behavior in Smilodon fatalis revealed by high-resolution 3D computer simulation. Proceedings of the National Academy of Sciences 104, 16010-16015.

Metzger, K.A., Daniel, W.J.T., Ross, C.F., 2005. Comparison of beam theory and finite element analysis with in vivo bone strain data from the alligator cranium. The Anatomical Record Part A: Discoveries in Molecular, Cellular, and Evolutionary Biology 283, 331-348.

Moreno, K., Wroe, S., Clausen, P., McHenry, C., D’Amore, D.C., Rayfield, E.J., Cunningham, E., 2008.

Cranial performance in the Komodo dragon (Varanus komodoensis) as revealed by high-resolution 3D finite element analysis. Journal of Anatomy 212, 736-746.

Nachtigall, P.E., 1980. Odontocete echolocation performance on object size, shape and material, Animal sonar systems. Springer, pp. 71-95.

Norris, K.S., 1968. The evolution of acoustic mechanisms in odontocete cetaceans. Evolution and environment, 297-324.

Pierce, S.E., Angielczyk, K.D., Rayfield, E.J., 2008. Patterns of morphospace occupation and mechanical performance in extant crocodilian skulls: a combined geometric morphometric and finite element modeling approach. Journal of morphology 269, 840-864.

Porro, L.B., Holliday, C.M., Anapol, F., Ontiveros, L.C., Ontiveros, L.T., Ross, C.F., 2011. Free body analysis, beam mechanics, and finite element modeling of the mandible of Alligator mississippiensis. Journal of Morphology 272, 910-937.

Rayfield, E.J., Milner, A.C., Xuan, V.B., Young, P.G., 2007. Functional morphology of spinosaur 'crocodile-mimic'dinosaurs. Journal of Vertebrate Paleontology 27, 892-901.

Reed, D.A., Porro, L.B., Iriarte-Diaz, J., Lemberg, J.B., Holliday, C.M., Anapol, F., Ross, C.F., 2011. The impact of bone and suture material properties on mandibular function in Alligator mississippiensis: testing theoretical phenotypes with finite element analysis. Journal of Anatomy 218, 59-74.

Seagars, 1982. Jaw structure and functional mechanics of six delphinids (Cetacea: Odontoceti). San Diego State University.

Soons, J., Herrel, A., Genbrugge, A., Aerts, P., Podos, J., Adriaens, D., de Witte, Y., Jacobs, P., Dirckx, J., 2010. Mechanical stress, fracture risk and beak evolution in Darwin's ground finches (Geospiza). Philosophical Transactions of the Royal Society B: Biological Sciences 365, 1093-1098.

Thomason, J., 1991. Cranial strength in relation to estimated biting forces in some mammals. Canadian Journal of Zoology 69, 2326-2333.

van Drongelen, W., Dullemeijer, P., 1982. The feeding apparatus of Caiman crocodilus; a functionalmorphological study. Anatomischer Anzeiger 151, 337-366.

Walmsley, C.W., McCurry, M.R., Clausen, P.D., McHenry, C.R., 2013a. Beware the black box: investigating the sensitivity of FEA simulations to modelling factors in comparative biomechanics. PeerJ 1, e204.

Walmsley, C.W., Smits, P.D., Quayle, M.R., McCurry, M.R., Richards, H.S., Oldfield, C.C., Wroe, S., Clausen, P.D., McHenry, C.R., 2013b. Why the long face? The mechanics of mandibular symphysis proportions in crocodiles. PLOS ONE 8, e53873.

Werth, A., 2000. A kinematic study of suction feeding and associated behaviour in the long finned pilot whale, Globicephala melas Marine Mammal Science 16, 299-314.

Werth, A., 2006a. Mandibular and dental variation and the evolution of suction feeding in Odontoceti. Journal of Mammalogy 87, 579-588. 
Werth, A.J., 2006b. Odontocete suction feeding: experimental analysis of water flow and head shape. Journal of Morphology 267, 1415-1428.

Young, M.T., Brusatte, S.L., Beatty, B.L., De Andrade, M.B., Desojo, J.B., 2012. Tooth-On-Tooth Interlocking Occlusion Suggests Macrophagy in the Mesozoic Marine Crocodylomorph Dakosaurus. The Anatomical Record: Advances in Integrative Anatomy and Evolutionary Biology 295, 1147-1158. Zapata, U., Metzger, K., Wang, Q., Elsey, R.M., Ross, C.F., Dechow, P.C., 2010. Material properties of mandibular cortical bone in the American alligator, Alligator mississippiensis. Bone 46, 860-867.

Table 1: Total muscle forces applied to each of the models during the bite force scaled results.

\begin{tabular}{|l|l|l|l|}
\hline & \multicolumn{3}{|c|}{ Muscle force (N) } \\
\hline & Anterior & Middle & Posterior \\
\hline Orcinus orca & 2405 & 2511 & 2270 \\
\hline $\begin{array}{l}\text { Lagenorhynchus } \\
\text { australis }\end{array}$ & 1473 & 2972 & 2221 \\
\hline Stenella longirostris & 6444 & 5331 & 3195 \\
\hline Inia geoffrensis & 2275 & 2153 & 1159 \\
\hline Osteolaemus tetraspis & 3488 & 2654 & 1919 \\
\hline $\begin{array}{l}\text { Crocodylus } \\
\text { novaeguineae }\end{array}$ & 3300 & 3286 & 3104 \\
\hline Mecistops cataphractus & 3548 & 3548 & 3548 \\
\hline Tomistoma schlegelii & 4374 & 4042 & 2910 \\
\hline
\end{tabular}

\section{Figure Captions}

Figure 1: Comparison of the skulls of longirostrine and brevirostrine crocodilians and odontocetes

with the pan bone and pterygoid flanges identified. A: the killer whale (Orcinus orca), B: the Amazon

River dolphin (Inia geoffrensis), C: the dwarf crocodile (Osteolaemus tetraspis) and D: the false gharial (Tomistoma schlegelii). 
Figure 2: Loading simulations shown on the skull of Inia geoffrensis. Blue points represent the bite points where either loads or restraints are placed depending on the loading conditions, note that the degrees of freedom of the constrains change between load cases and that only one set of bite point constraints (anterior, middle or posterior) are present in each load case. Red points represent the location of restraints on the occipital condyle. A: Bite loading where forces are applied through simulated muscles B: Shake loading where a force of $400 \mathrm{~N}$ was applied to the teeth in a lateral direction C: twist loading where a rotational moment of $400 \mathrm{Nmm}$ was applied to the occipital condyle.

Figure 3: Strain patterns during bite load cases scaled to the same bite force at the anterior $(\mathrm{A}-\mathrm{H})$, middle (I-P) and posterior ( $\mathrm{Q}-\mathrm{X})$ bite positions. Hotter colours correspond to areas with higher levels of von Mises strain. Note that the limits of the strain displayed vary with load case. Top of each panel from left to right Odontocetes: Orcinus orca, Lagenorhynchus australis, Stenella longirostris, Inia geoffrensis. Bottom of each panel from left to right Crocodilians: Osteolaemus tetraspis, Crocodylus novaeguineae, Mecistops cataphractus and Tomistoma schlegelii. Note the similarity in the locations and magnitudes of strain between corresponding morphotypes of crocodilian and odontocete.

Figure 4: A: Strain levels in the cranium and mandible during bite force scaled load cases. A: at the anterior teeth and B: at mid tooth row and C: at the posterior teeth. From left to right Odontocetes: Orcinus orca, Lagenorhynchus australis, Stenella longirostris, Inia geoffrensis and Crocodilians: Osteolaemus tetraspis, Crocodylus novaeguineae, Mecistops cataphractus and Tomistoma schlegelii. Silhouettes show the cranial morphology of each specimen in dorsal view. 
Figure 5: A: Strain levels in the cranium and mandible during muscle force scaled load cases. A: at the anterior teeth and B: at mid tooth row and C: at the posterior teeth. From left to right Odontocetes: Orcinus orca, Lagenorhynchus australis, Stenella longirostris, Inia geoffrensis and Crocodilians: Osteolaemus tetraspis, Crocodylus novaeguineae, Mecistops cataphractus and Tomistoma schlegelii. Silhouettes show the cranial morphology of each specimen in dorsal view.

Figure 6: Strain patterns during extrinsic load cases in shake loading. Anterior (A-H) and middle (I-P) tooth positions. Hotter colours correspond to areas with higher levels of von Mises strain. Top of each panel from left to right Odontocetes: Orcinus orca, Lagenorhynchus australis, Stenella longirostris, Inia geoffrensis. Bottom of each panel from left to right Crocodilians: Osteolaemus tetraspis, Crocodylus novaeguineae, Mecistops cataphractus and Tomistoma schlegelii. Note the similarity in the locations and magnitudes of strain between corresponding morphotypes of crocodilian and odontocete.

Figure 7: Strain levels in the cranium and mandible during shake load cases. A: at the anterior teeth and B: at mid tooth row. From left to right Odontocetes: Orcinus orca, Lagenorhynchus australis, Stenella longirostris, Inia geoffrensis and Crocodilians: Osteolaemus tetraspis, Crocodylus novaeguineae, Mecistops cataphractus and Tomistoma schlegelii. Silhouettes show the cranial morphology of each specimen in dorsal view. Note the consistent effect of longirostry when loaded at the anterior position.

Figure 8: Strain patterns during extrinsic load cases in twist loading. Anterior (A-H) and middle (I-P) tooth positions. Hotter colours correspond to areas with higher levels of von Mises strain. Top of each panel from left to right Odontocetes: Orcinus orca, Lagenorhynchus australis, Stenella 
longirostris, Inia geoffrensis. Bottom of each panel from left to right Crocodilians: Osteolaemus tetraspis, Crocodylus novaeguineae, Mecistops cataphractus and Tomistoma schlegelii. Note the similarity in the locations and magnitudes of strain between corresponding morphotypes of crocodilian and odontocete.

Figure 9: Strain levels in the cranium and mandible during twist load cases. A: at the anterior teeth and B: at mid tooth row. From left to right Odontocetes: Orcinus orca, Lagenorhynchus australis, Stenella longirostris, Inia geoffrensis and Crocodilians: Osteolaemus tetraspis, Crocodylus novaeguineae, Mecistops cataphractus and Tomistoma schlegelii. Silhouettes show the cranial morphology of each specimen in dorsal view. Note the consistent effect of longirostry when loaded at the anterior position. 
A
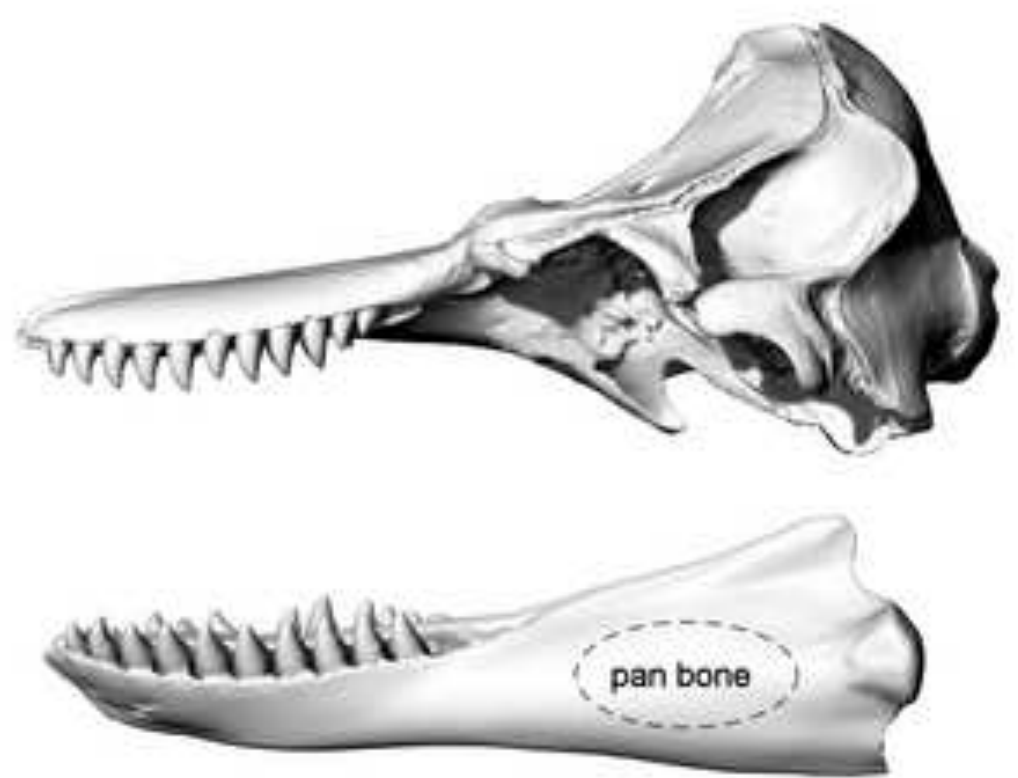

C
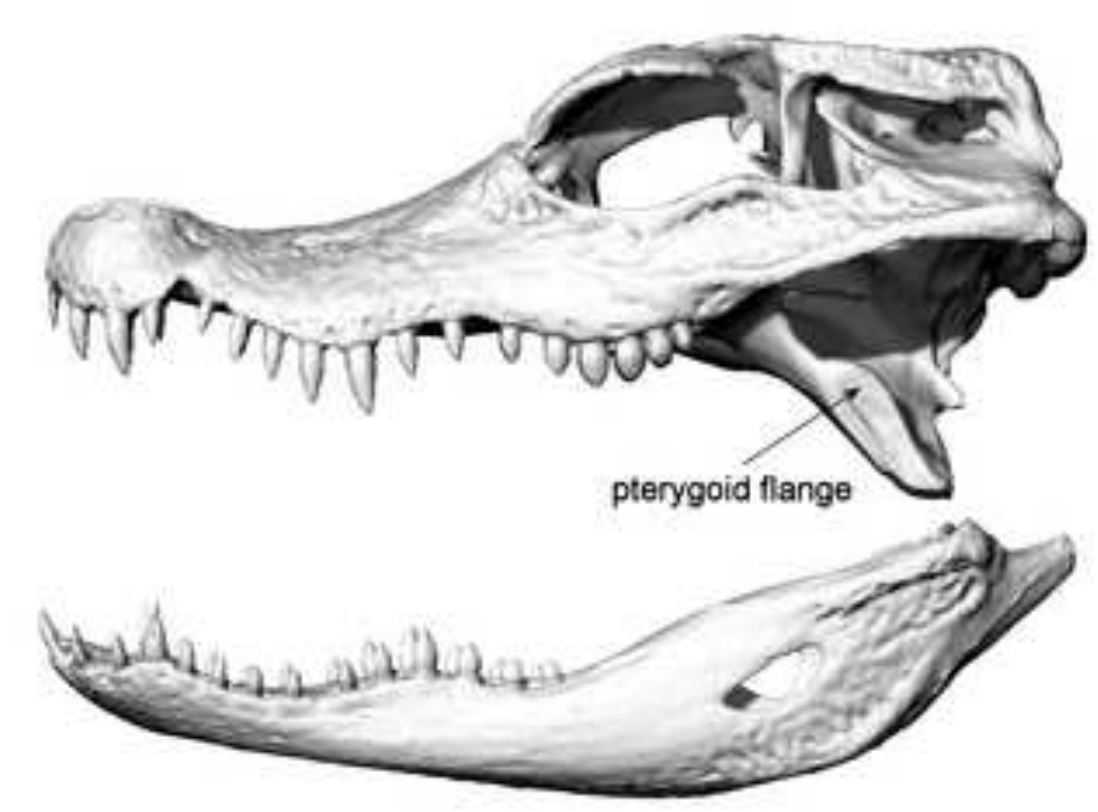

B

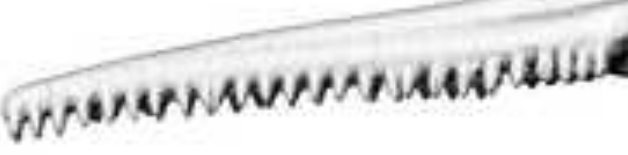
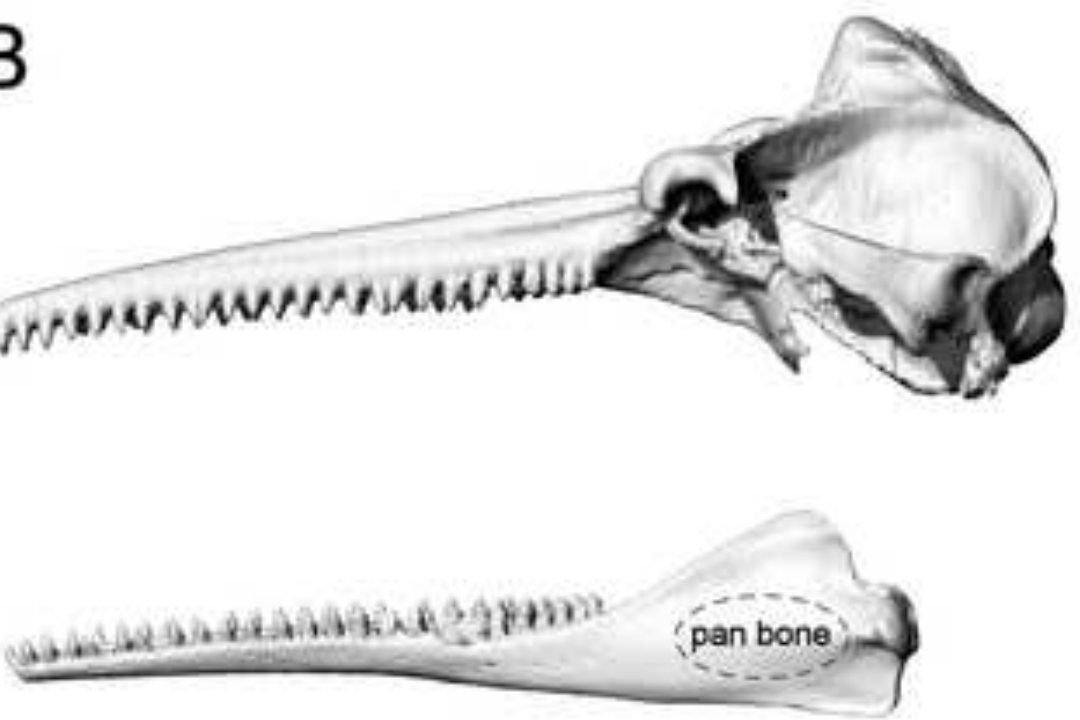

D
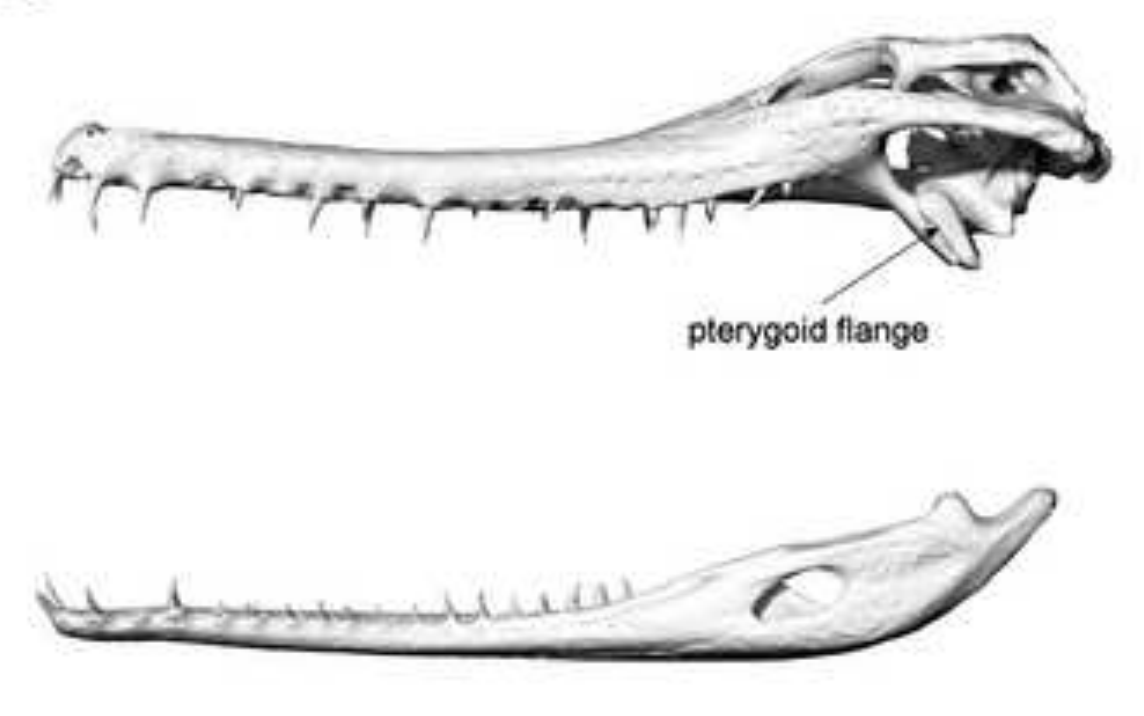

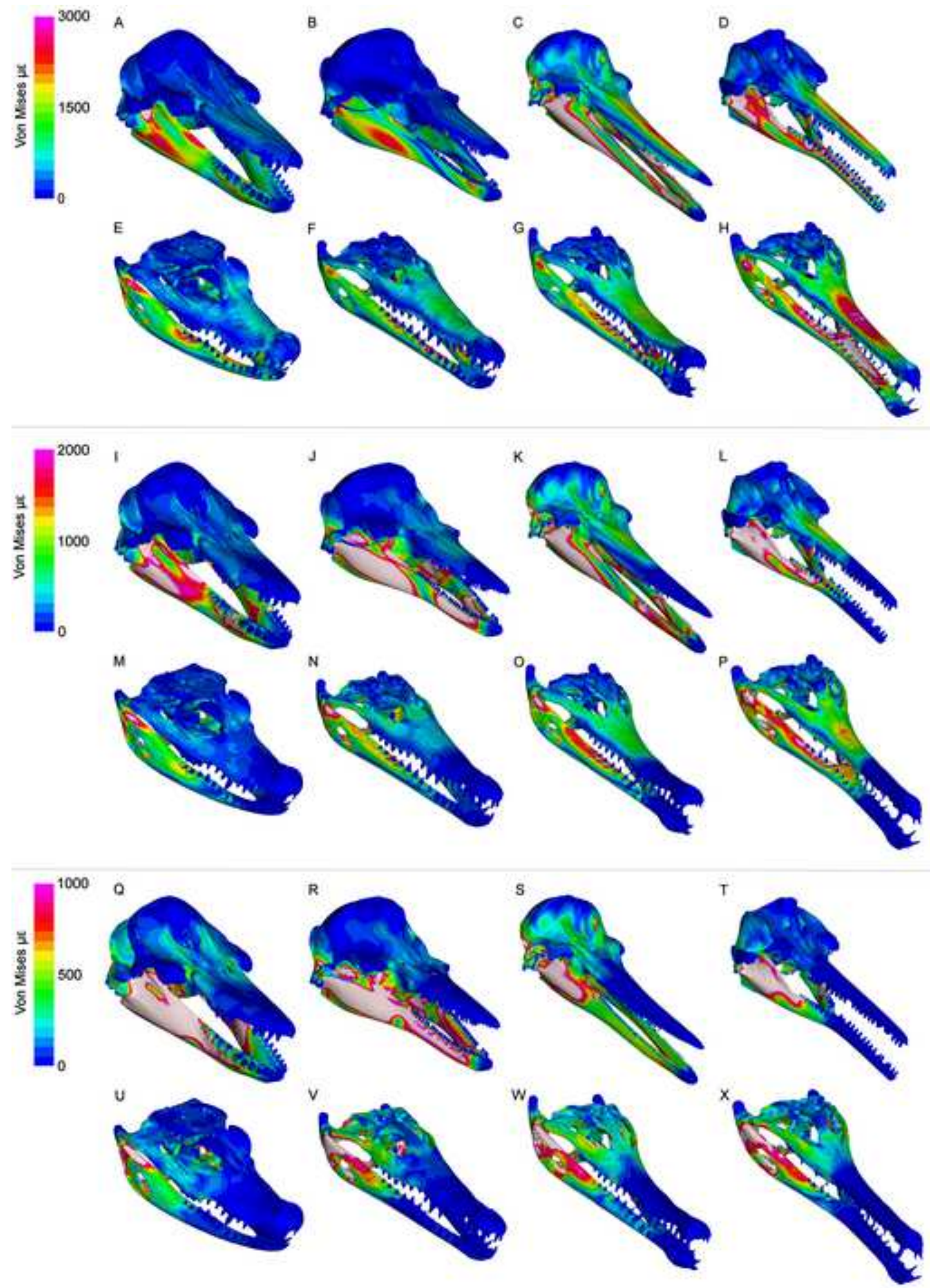
Figure 4
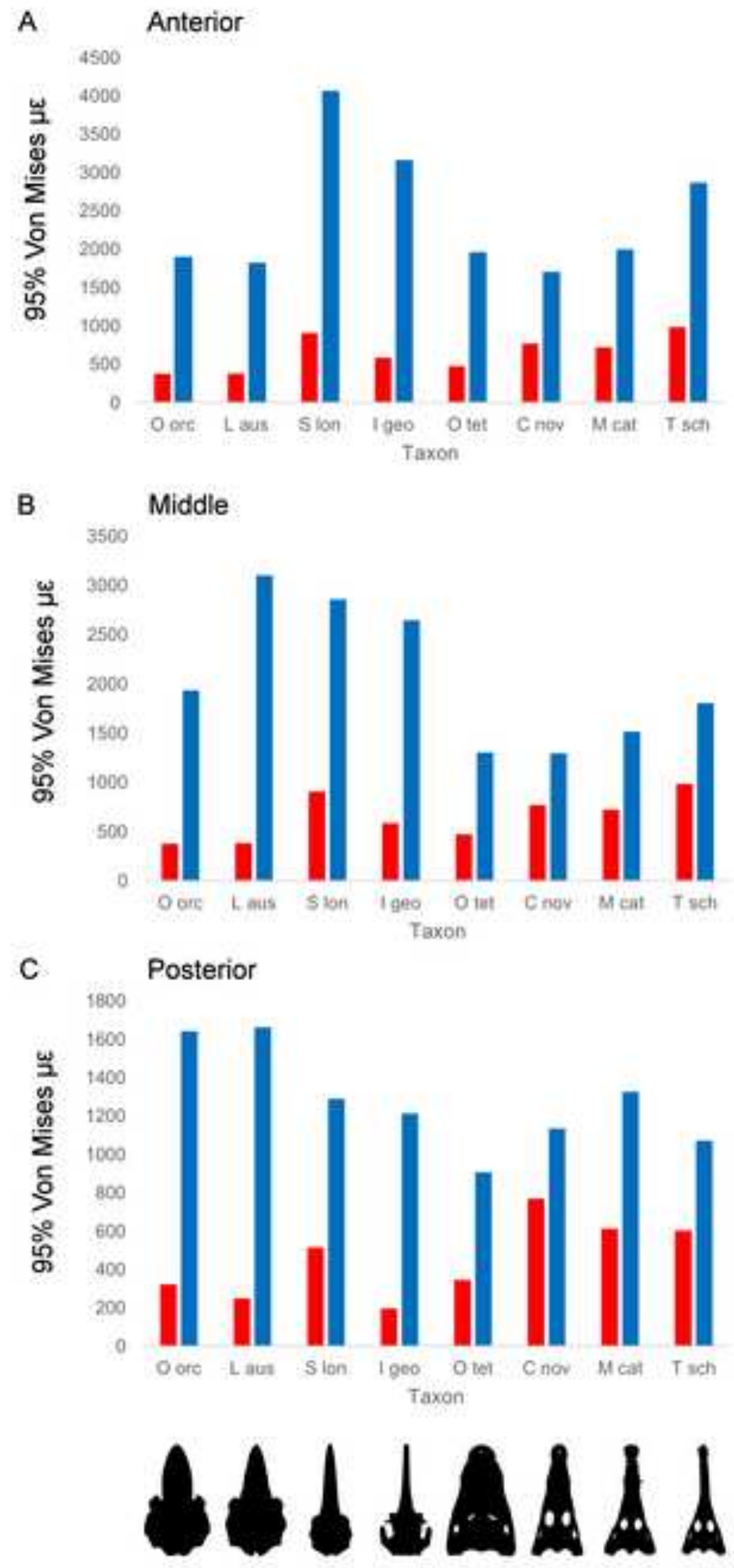

- cranium andible

Legend 
Figure 5
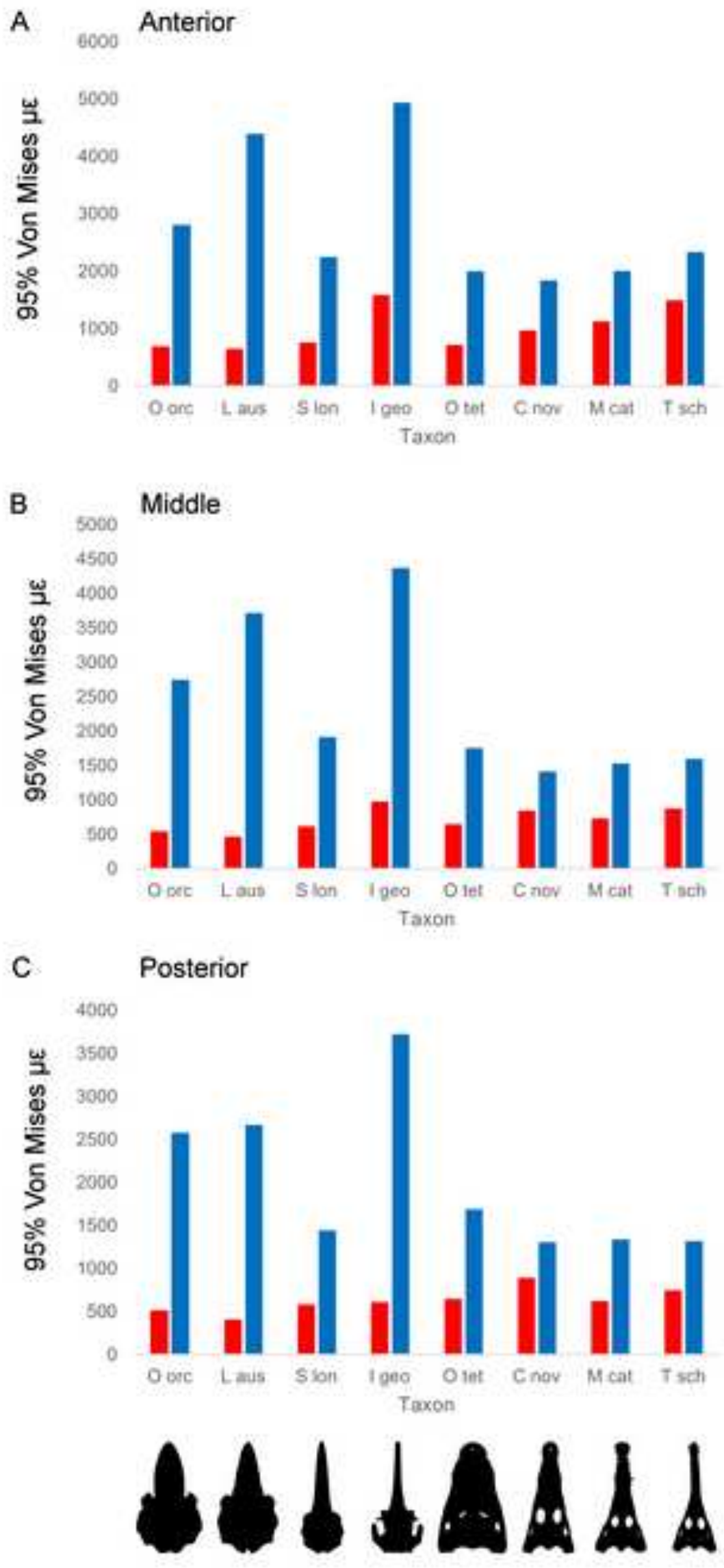

- cranium andible

Legend 

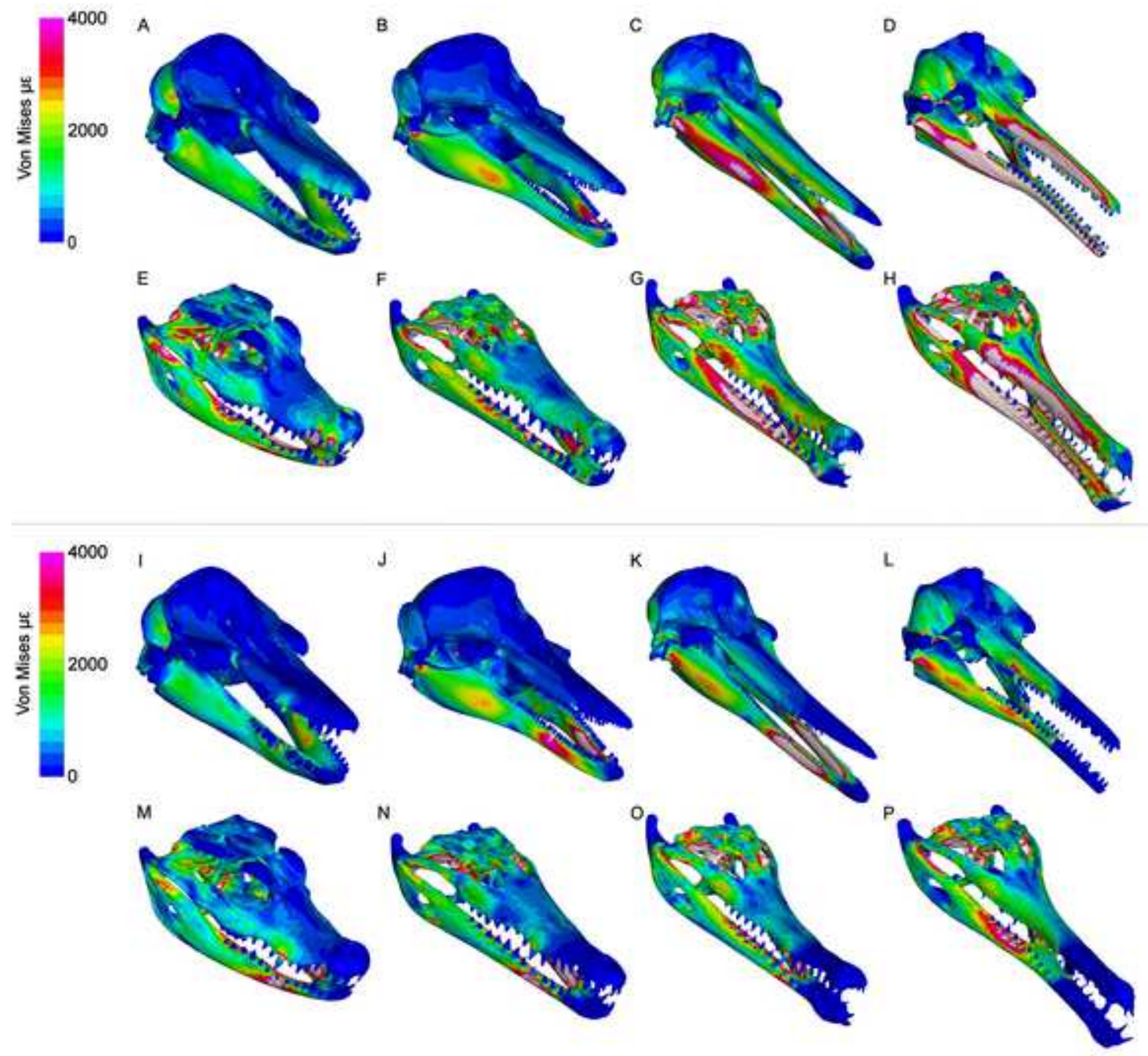

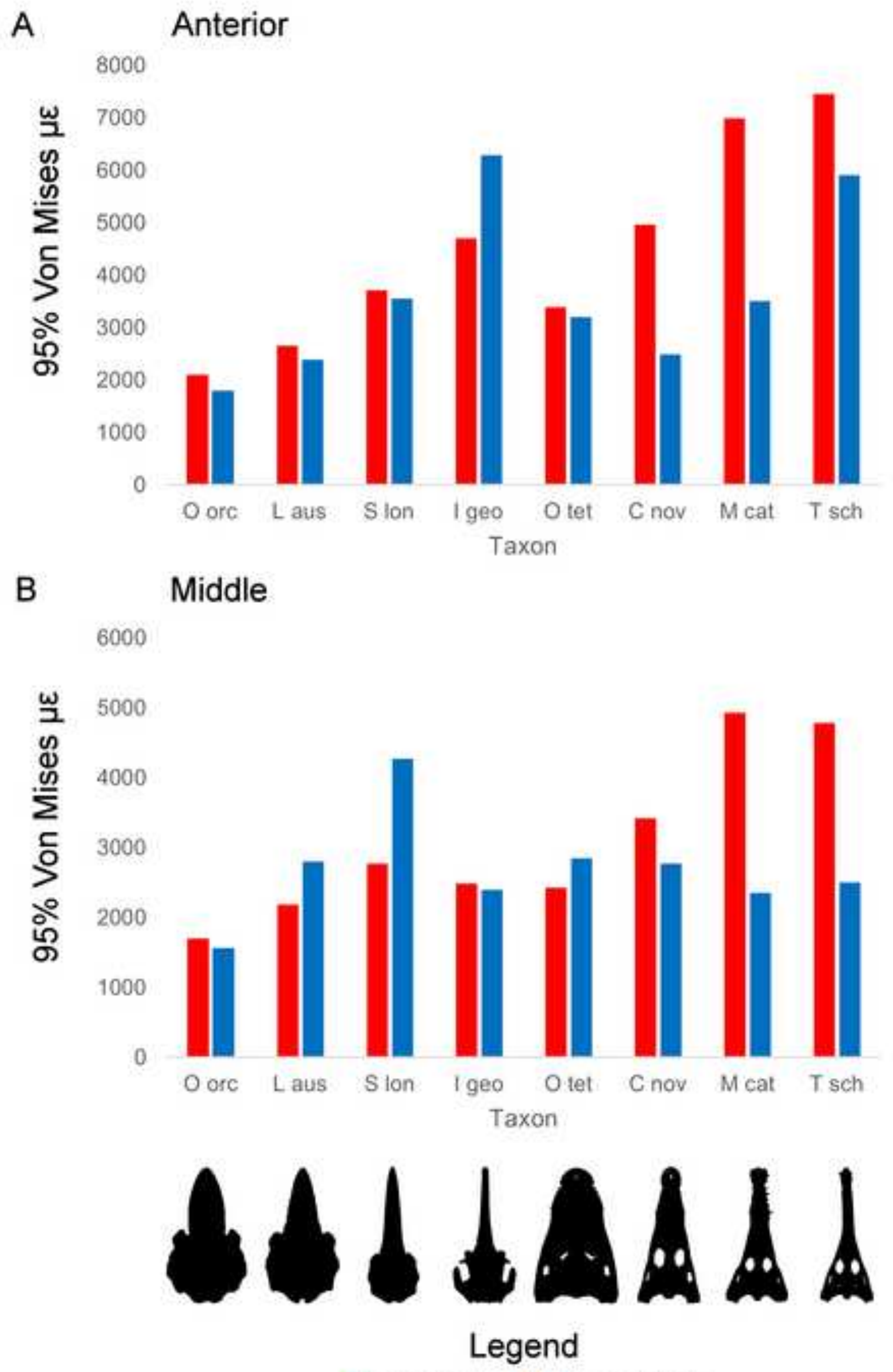

v cranium mandible 

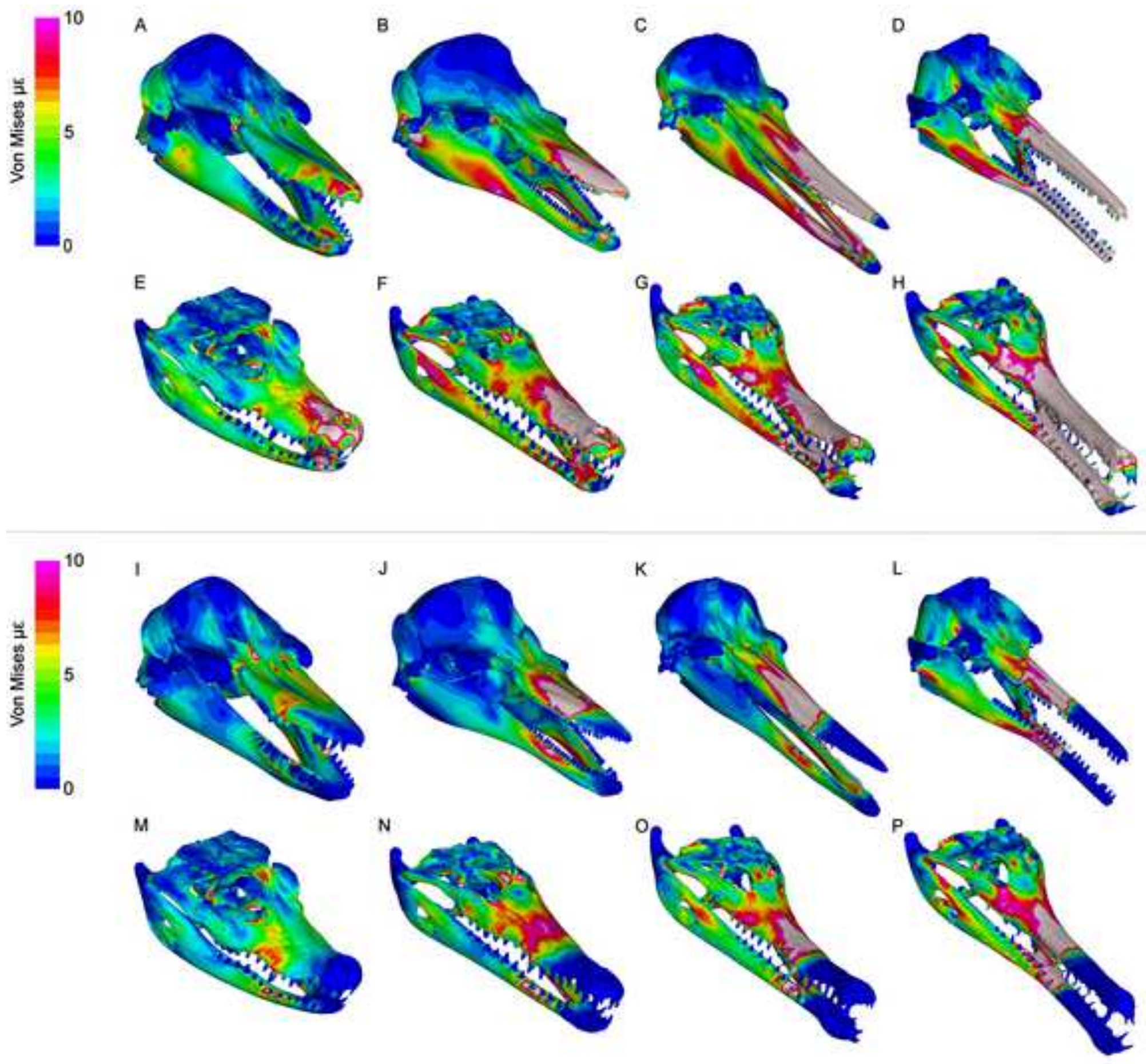


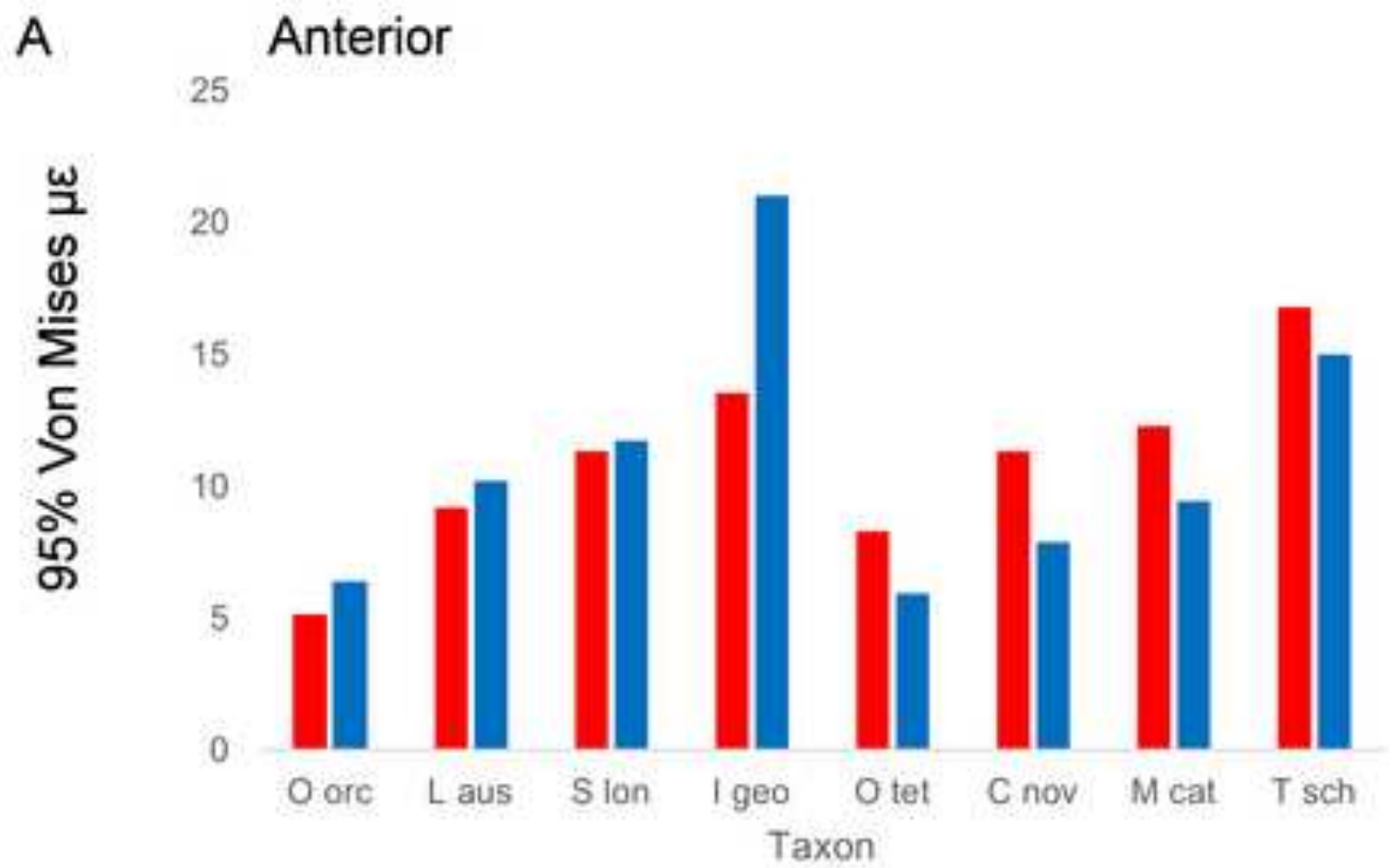

B Middle 12
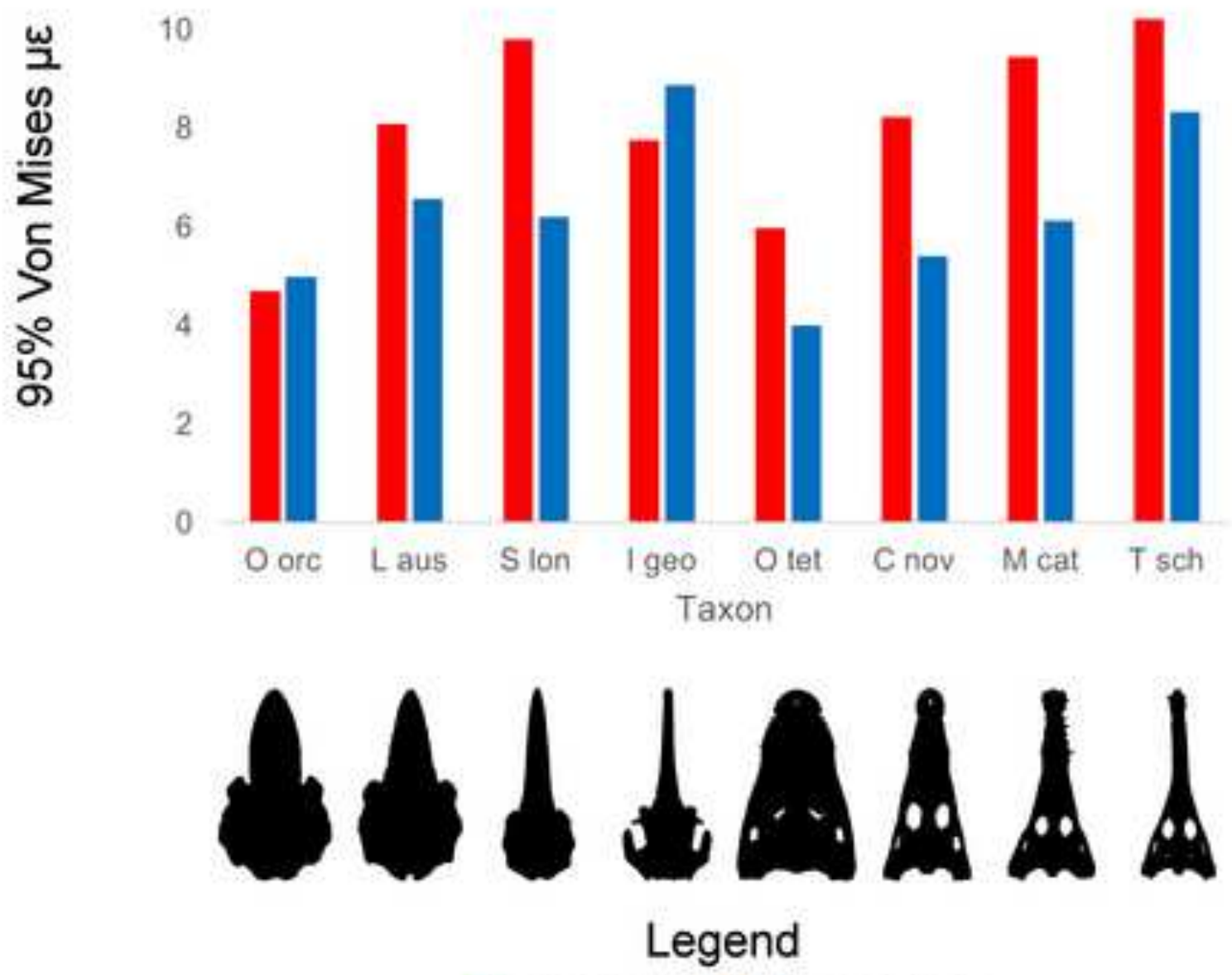

- cranium mandible 